\title{
The Protective Role of Ursodeoxycholic Acid versus Seleniumon The Methotrexate Hepatotoxicity in Adult Male Albino Rat: Histological, Immunohistochemical and Histomorphmetric Study
}

\author{
HANAN N. GADALLAH, M.D. \\ The Department of Anatomy and Embryology, Faculty of Medicine, Cairo University
}

\begin{abstract}
Background: Methotrexate (MTX) isa folic acid antagonist withanti-inflammatory, anti-proliferative and immunosuppressive activities. MTX is very effective in the treatment of many inflammatory disordersand types of canceras it depleted thehepatic folate stores needed for DNA and protein synthesis. However, this drug has profoundly toxic effect particularly to the liver. Treatment with Ursodeoxycholic Acid (UDCA), a hydrophilic bile acid, is widely used due to its defensive mechanismof liver toxicity. Selenium (Se), one of the essential trace elements, has a protective role as antioxidant in the body.
\end{abstract}

Aim of Study: The present work was designed to evaluate the adverse effect of Methotrexate on the histology of the liver and to investigate the possible protective role of Ursodeoxycholic acid versus Selenium on Methotrexate-induced hepatic toxicity.

Material and Methods: Twenty-four adult male albino rats were utilized in the present study. The rats were divided into four groups, each group consisted of six rats. Group I (control group), Group II (receiving Methotrexate only), Group III (Ursodeoxycholic acid -treated group), Group IV (Selenium-treated group). The livers of all rats were removed for investigation using light microscopic, immunohistochemical, histomorphometrical and statistical studies.

Results and Conclusion: Methotrexate receiving rats showed massive degenerative changes and loss of demarcation of the hepatocytes. These changes had been partially recovered in rats treated with Ursodeoxycholic acid. Therefore, using Selenium, the degenerative changes were much reduced. The present study concluded that Selenium was more effective in improving the structural changes in rats receiving Methotrexate.

Key Words: Methotexate - Liver - Ursodeoxycholic acid and Selenium.

\section{Introduction}

METHOTREXATE (MTX)-formerly known as amethopterin-was reported to be a folic acid antag-

Correspondence to: Dr. Hanan N. Gadallah,

E-Mail: hanan.nabih2010@gmail.com onist havinganti-inflammatory, anti-proliferative and immunosuppressive effects. Methotrexate was found to be very effective in the treatment of Rheumatoid Arthritis (RA), Psoriatic Arthritis (PsA) and Crohn's disease. Methotrexate was with a great benefit in improving the disease course, patient's quality of life, and reducing morbidity and mortality $[\mathbf{1 , 2}]$. However, this popular and relatively safe drug might have toxic effects particularly on the liver; liver fibrosis and cirrhosis was found to be a major obstacle secondary to the symptoms of gastrointestinal disturbances [3].

Methotrexate performed its anti-inflammatory effect, through the release of adenosine, rather than anti-metabolite [4]. However, even low dose of MTX was associated with hepatic side effect indicated by elevated liver enzymes [5].

Methotrexate was found to be very essential for the treatment of acute lymphoblastic leukemia, osteosarcoma and lymphomas. By this, its action was explained as an antimetabolite; it interfered with the metabolism of folic acid and bound to dihydrofolatereductase more than that of folate. At the same time, MTX was used to inhibit the conversion of dihydrofolate to tetrahydrofolate which was essential for the biosynthesis of thymidine and purines and needed for the synthesis of DNA. Hence, the cells were unable to divide and to form proteins $[6,7]$.

Ursodeoxycholic Acid (UDCA) was known to be a dihydroxy ( 3 (x, 70 -dihydroxy-5 0 cholan-24oic acid) bile acid that formed about $4 \%$ of the total bile acid stores. UDCA had a cytoprotective effect as it prevented the toxic side effects of other hydrophobic bile acids [8]. Thus, it was widely used in the treatment of many chronic cholestatic diseases as primary biliary cirrhosis, primary scle- 
rosing cholangitis and drug-induced cholestasis [9].

UDCA treatment relatively stopped the progress of liver fibrosis as it possessed anti-fibrotic activity as it inhibited fibrogenesis. Therefore, UDCA used in the treatment of the immune-mediated liver fibrosis as it inhibited the expression of collagen and other components of the extracelluar matrix [10,11]. Moreover, UDCA could improve apoptosis and inflammation by reduction in cytokines production as tumor necrosis factor-alpha ( $\mathrm{TNFa}$ ) $[12,13]$.

Selenium (Se), is one of the essential trace elements, was found to be very necessary for human for its antioxidant effect and its ability to stop the growth and metastasis of cancers with less marked toxicity $[\mathbf{1 4 , 1 5}]$

The antioxidant effect of Se was explained by its ability to reduce serum C-reactive protein and pro-inflammatory cytokines in the liver, thus preventing liver injury and the histological changes due to oxidative stress. Consequently, Se could also deter the progression and severity of liver injury during acute inflammatory episodes [16].

The attention of literatures to the protective effect of Se against the hepatotoxicity from oxidative stress inducing and necrotic substances was increasing. The protective role was explained by the fact that Se increased the activity of glutathione peroxidase [17]. Recently, Se was included in the structure of many enzymes as Glutathione Peroxidase (GPx) and thioredoxine that played an important role in the defensive mechanisms against cellular oxidative stress [18].

\section{Material and Methods}

\section{Material:}

I- Chemicals:

1- Methotrexate, was obtained from Hikma Pharmaceutical Co., in the form of vials (Unitrexate). Each vial contains $25 \mathrm{mg}$ Methotrexate dissolved in $1 \mathrm{ml}$ solution. It was given by IM injection once weekly in adose of $10 \mathrm{mg} / \mathrm{kg}$ body weight for 4 weeks [19].

2- Ursodeoxycholic acid, was obtained from Minapharm Pharmaceutical Co., in the form of capsules (Ursoplus). The drug was ingested via gastric intubation once daily in a dose of $20 \mathrm{mg} / \mathrm{kg}$ body weight for 4 weeks [20]

3- Selenium, was purchased from Inter Pharma UK Co., in the form of film coated tablets (Selenium-ACE). The drug was ingested via gastric intubation once daily in a dose of $0.05 \mathrm{mg} / \mathrm{kg}$ body weight for 4 weeks [21]

\section{II- Animals:}

The present study was carried out on twentyfour adult male albino rats weighing 200-350gm. The animals were housed in cages under standard laboratory and environmental conditions with free access to food and water.

\section{III- Experimental design:}

The rats were segregated into four groups (6 rats each);

- Group I (control group): Supplemented with standard diet only.

- Group II: Receiving Methotrexate IM injection once weekly in a dose of $10 \mathrm{mg} / \mathrm{kg}$ body weight for 4 weeks.

- Group III: Receiving Methotrexate and Ursodeoxycholic acid; IM injection of Methotrexate weekly in a dose of $10 \mathrm{mg} / \mathrm{kg}$ body weight for 4 weeks and ingested at the same time Ursodeoxycholic acid by gastric lavage in a daily dose of $15 \mathrm{mg} / \mathrm{kg}$ body weight for the same period.

- Group IV: Receiving Methotrexate and Selenium; IM injection of Methotrexate weekly in a dose of $10 \mathrm{mg} / \mathrm{kg}$ body weight for 4 weeks and ingested at the same time Selenium by gastric lavage in a daily dose of $0.05 \mathrm{mg} / \mathrm{kg}$ body weight for the same period.

By the end of the experimental period, the rats were sacrificed by decapitation and livers were excised.

\section{Methods:}

\section{Light microscopic studies:}

Specimens from the livers were fixed in $10 \%$ formol saline, dehydrated in ethanol and embedded in paraffin. Paraffin sections were cut at $5 \mu \mathrm{m}$ thick mounted on slides and stained with;

1- Haematoxylin and eosin stain.

2- Masson's trichromestain for detection of collagen fibers in tissues.

3- Periodic Acid-Schiff (PAS) reagent for carbohydrate demonstration and many cell structures as glycogen.

\section{Immunohistochemical study:}

1- Alpha Smooth muscle actin ( (xSMA) for detection of the activated HSCs. It is ready to use rabbit polyclonal a SMA Ab (IgG) (product number ABT 1487, Sigma-Aldrich, Saint Louis, Misouri, USA). It is reactive to human, mouse and rat. 
2- Glial Fibrillary Acidic Protein (GFAP) for demonstration of HSCs. It is ready to use mouse monoclonal GFAP Ab (mouse IgG1 isotype) (product number G 3893, Sigma-Aldrich, Saint Louis, Misouri, USA). This antibody is reactive to human, pig and rat.

\section{Histomorphometric studies:}

1- The mean area and area percent of collagen: It was done using Masson's Trichrome stained sections. The area percent of collagen was measured using the image analyzer at a magnification of X100. Ten readings were obtained for each specimen of all animal groups.

2- The mean value of the optical density of the glycogen: The mean values of the optical density of the glycogen content in the hepatocytes in Periodic Acid Schiff (PAS)-stained sections were measured.

3- Mean area $\%$ of a SMA positive immunoreactions in a SMA immune-stained section.

4- Mean area \% of GFAP positive immunoreactions in GFAP immune-stained section.

\section{Statistical analysis:}

Values were presented as mean, Standard Deviation (SD) and confidence intervals values. Data were explored for normality using KolmogorovSmirnov test of normality. The results of Kolmogorov-Smirnov test indicated that data were normally distributed (parametric data), therefore, one way analysis of variance (ANOVA) was used to compare between groups.

The significance level was set at $p<0.05$. Statistical analysis was performed with SPSS 18.0 (Statistical Package for Scientific Studies, SPSS, Inc., Chicago, IL, USA) for Windows.

This study was conducted at the Department of Anatomy, Faculty of Medicine, Cairo University, from March 2019-March 2020.

\section{Results}

\section{Histological results:}

Group I (control group): The liver was seen of normal hepatic architecture. The hepatocytes were observed arranged in cords radiating from the central vein. The hepatic cords were separated from each other by blood sinusoids which were lined with endothelial cells and Von kupffer cells. Hepatocytes werepolygonal witheosinophilic cytoplasm and large, central, rounded vesicular nuclei Fig. (1).
Masson's trichrome stained sections showed thin layer of collagen fibers around the periportalarea Fig. (8A).

PAS-stained sections demonstrated strong positive PAS reaction of the glycogen content in the hepatocytes Fig. (10A).

Group II (Methotrexate-treated group): Methotrexate-treated group showed dilated central vein with areas of extravasation of blood and cellular debris Fig. (2). The surrounding hepatocytes appeared irregular, degenerated with loss of demarcation Figs. $(2,3)$. The degenerative changes were in the form of nuclear ghosts (Karyolysis), and vacuolated cytoplasm. Few hepatocytes showed dark nuclei with deeply acidophilic cytoplasm Figs. $(2,3)$. Nuclear inflammatory cellular infiltration was also detected in between the hepatocytes Figs. $(2,3)$ and around the portal space Figs. $(4,5)$. Congestion and dilatation of the portal vein was demonstrated Figs. $(4,5)$ with branch of hepatic artery and branch of bile duct Fig. (5). The blood sinusoids in between the hepatocytes were observed dilated Fig. (2).

Masson's trichrome stained sections showed marked deposition of collagen fibers in and around expanded portal tract, with dilatation of the portal vein tributaries Figs. $(8 \mathrm{~B}, \mathrm{C})$.

Weak PAS reaction was observed indicating decreased glycogen content in the hepatocytes Fig. (10B).

Group III (Methotrexate with Ursodeoxycholic acid-treated group): Normal cords of hepatocytes radiating from slightly dilated central vein were observed. Areas of extravasation of blood were detected Fig. (6A). Some hepatocytes showeddegeneration and loss of demarcation with vacuolated cytoplasmic Fig. (6B).

Masson's trichrome stained sections showed minimal amount of collagen fibers surrounding the portal area Fig. (9A).

Moderate positive PAS reaction in the hepatocytes was demonstrated indicating increase in the glycogen content Fig. (10C).

Group IV (Methotrexate with Selenium-treated group): Apparently normal cords of hepatocytes radiating from slightly dilated central vein were seen. Some hepatocytes show degeneration and loss of demarcation with vacuolated cytoplasmic Fig. (7). 
Masson's trichrome stained sections showed minimal amount of collagen fibers surrounding the portal area Fig. (9B).

PAS-stained sections revealed moderate positive PAS reaction in the hepatocytes indicating increase in the glycogen content Fig. (10D).

\section{Immunohistochemical study:}

1- a-SMA immuno-stained liver sections:

Group I (control group): Positive immunoreaction to a-SMA could only be detected in the wall of the central vein. There was no other positive immunoreaction detected Fig. (11A).

Group II (Methotrexate-treated group): Positive immunoreaction to a-SMA could be seenaround blood sinusoids (Fig. 11B).

Group III (Methotrexate with Ursodeoxycholic acid-treated group): Positive immunoreaction to a-SMA could be observedin the wall of the central vein. Moderate positive reaction was shown around blood sinusoids Fig. (11C).

Group IV (Methotrexate with Selenium-treated group): Positive immunoreaction to a-SMA could be demonstrated in the wall of the central vein. No positive reaction was seen around blood sinusoids Fig. (11D).

\section{2- Immuno-stained sections for GFAP:}

Group I (control group): GFAP positive stellate branched HSCs could only be illustrated around the blood sinusoids. No positive cells were observed at the portal area Fig. (12A).

Group II (Methotrexate-treated group): GFAP positive stellate branched HSCs could be shownaround the blood sinusoids. Positive cells were also seen in connective tissue around the portal area Fig. (12B).

Group III (Methotrexate with Ursodeoxycholic acid-treated group): GFAP positive stellate branched HSCs could be demonstrated around the blood sinusoids Fig. (12C).

Group IV (Methotrexate with Selenium-treated group): GFAP positive stellate branched HSCs could be observed around the blood sinusoids area. No positive cells were seen at the portal area Fig. (12D).
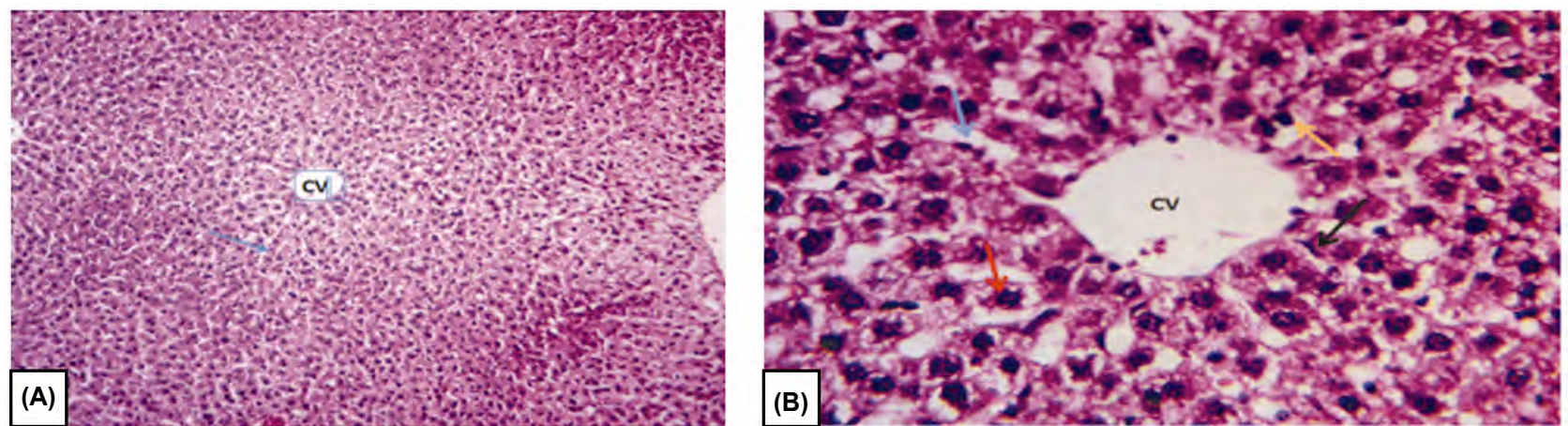

Fig. (1): (A,B): Micrograph of a rat liver (control group), showing hepatocytes are arranged in cords radiating from the central vein $(\mathrm{CV})$ and separated by blood sinusoids (blue arrow) that are lined by endothelial cells (black arrow) and Von Kuffer cells (orange arrow). Hepatocytesare polygonal with eosinophilic cytoplasm and large, central, rounded vesicular nuclei (red arrow). A- (Hx. \& E. X100). B- (Hx. \& E. X400)
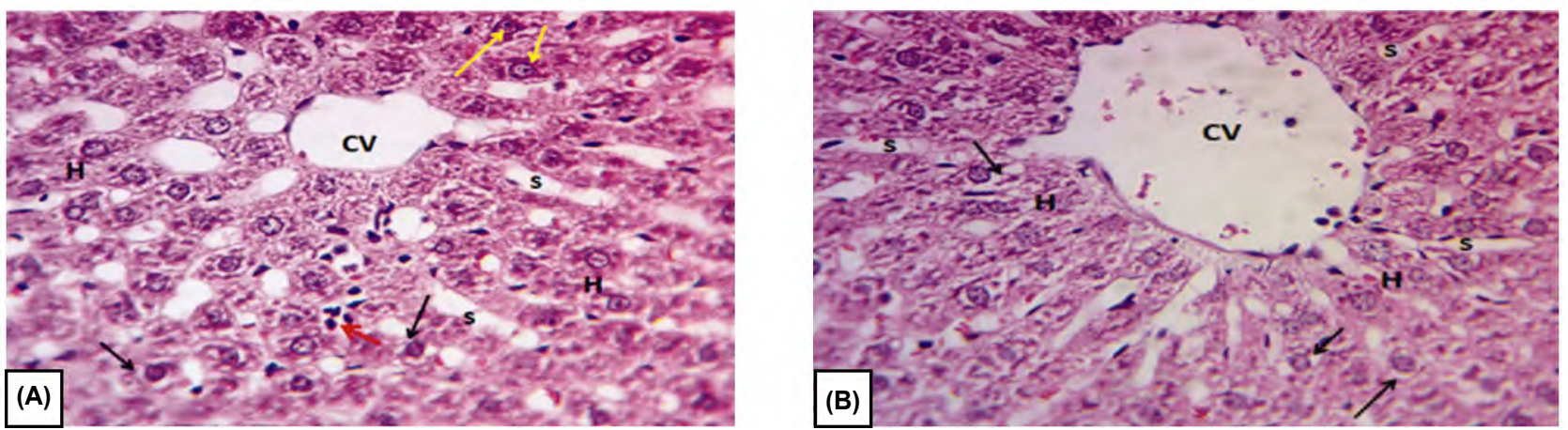

Fig. (2): (A \& B): Micrograph of a rat liver (group II), displaying dilated central vein (CV) with areas of extravasation of blood and cellular debris in (5b). Dilated, sinusoids (S) are also seen. Hepatocytes show marked degenerative changes and loss of demarcation with nuclear ghosts (Karyolysis) (H). Other hepatocytes show vacuolated cytoplasm (black arrows) and others are with dark nuclei (yellow arrows). Note: Inflammatory cellular infiltration (red arrow). (Hx. \& E. X400). 
Fig. (3): Micrograph of a rat liver (group II), illustrating inflammatory cellular infiltration (black arrow). The surrounding hepatocytes show degenerative changes with loss of demarcation $(\mathrm{H})$ and vacuolated cytoplasm (yellow arrows). Some hepatocytes show dark nuclei with deeply acidophilic cytoplasm (red arrows). (Hx. \& E. $\mathrm{X} 400$ )
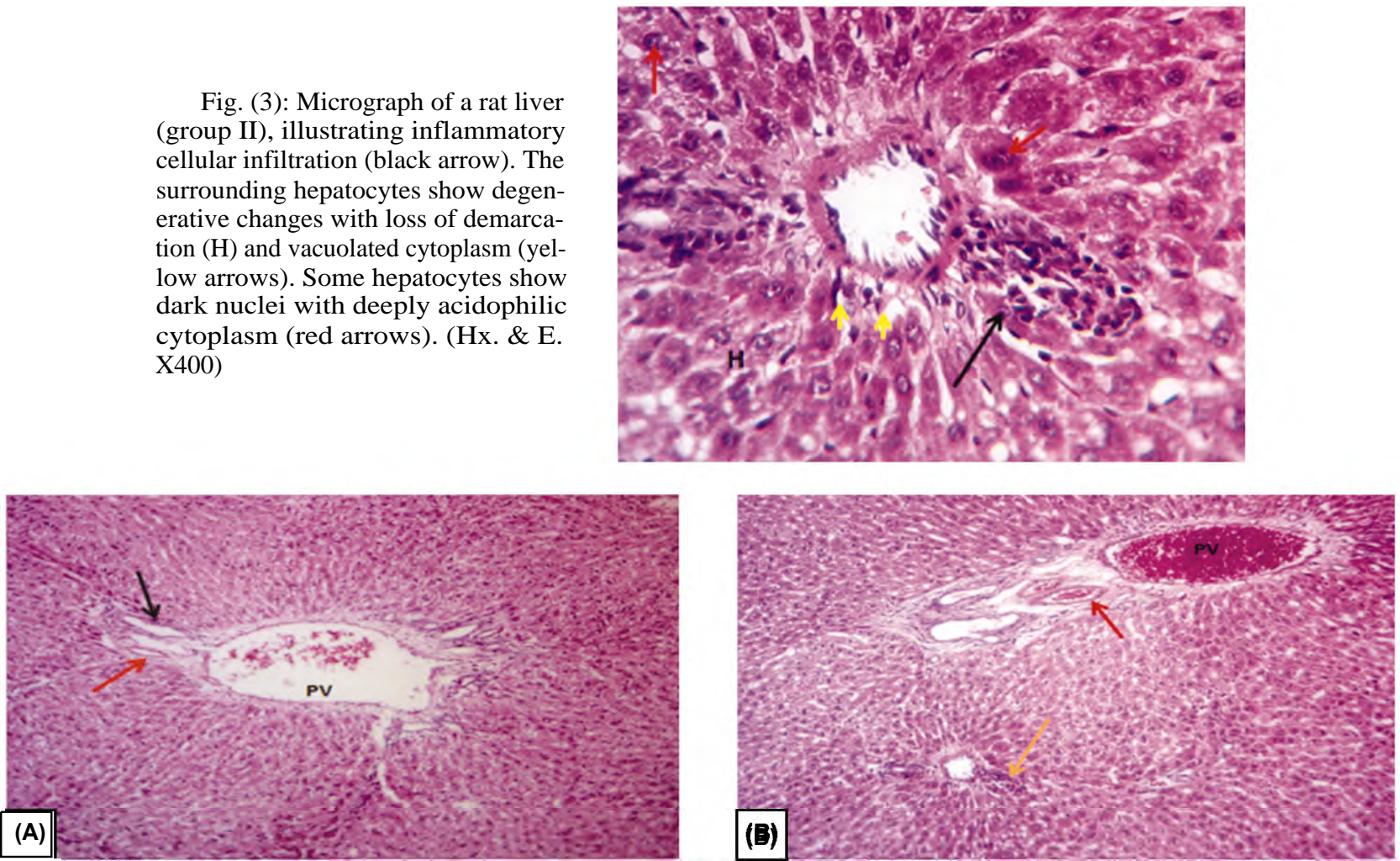

Fig. (4): (A,B): Micrograph of a rat liver (group II), displaying congested and dilated portal vein (PV). The hepatic artery (red arrow) and bile duct (black arrow) are also seen. Inflammatory cellular infiltration is observednear the central vein (orange arrow). (Hx. \& E. X100)

Fig. (5): Micrograph of a rat liver (group II), showing inflammatory cellular infiltration (black arrows) with thickened connective tissue (red star) around the portal area. Dilatedtributary of the portal vein (PV), branch of the hepatic artery (HA) and branch of the bile duct (D) are seen. (Hx. \& E. X400).
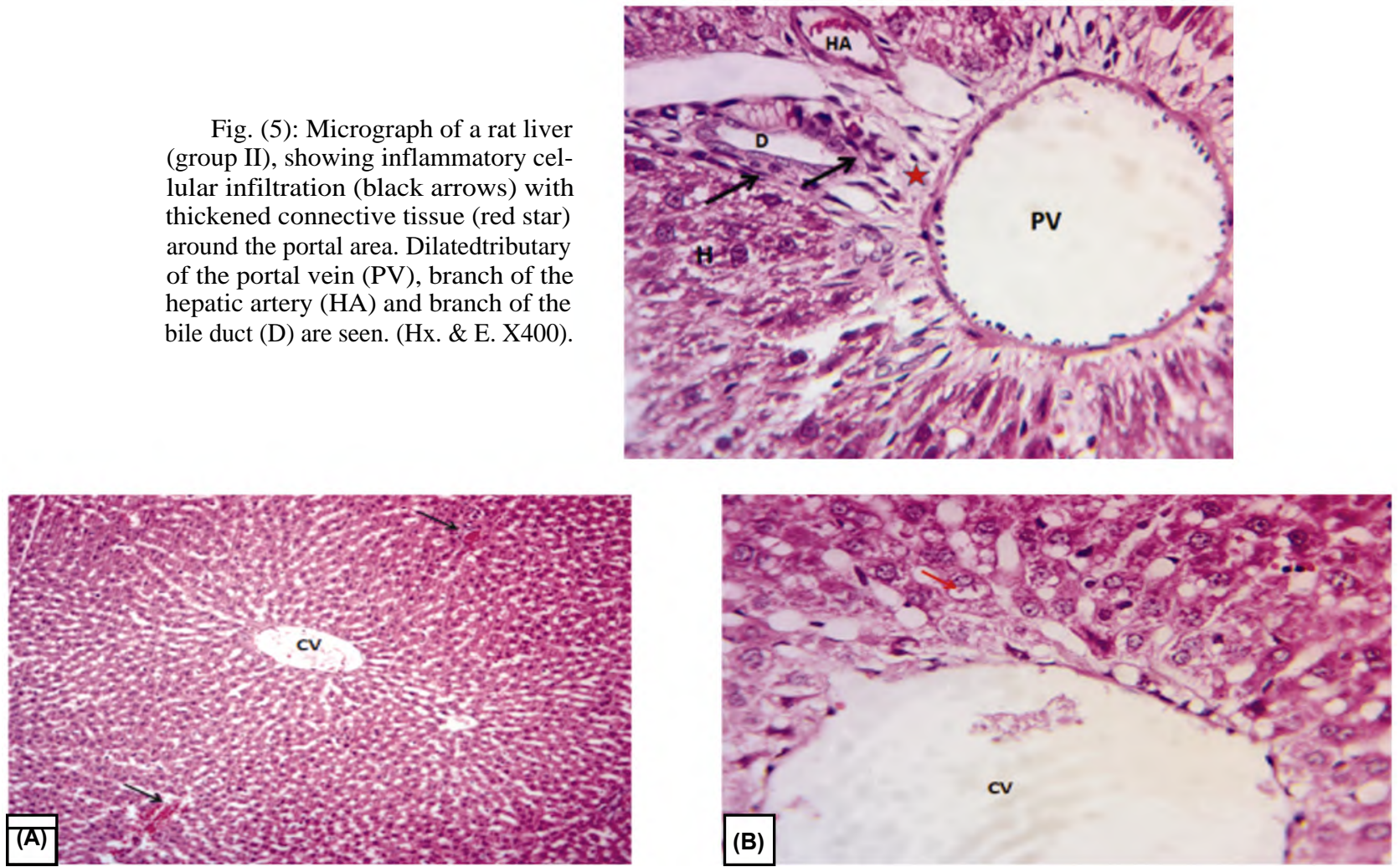

Fig. (6): (A,B): Micrograph of a rat liver (group III), presenting apparently normal cords of hepatocytes radiating from slightly dilated central vein $(\mathrm{CV})$. A- Areas of extravasation of blood in between the hepatocytes (black arrows). B- Some hepatocytes show degeneration and loss of demarcation with vacuolated cytoplasm (red arrow). A- (Hx. \& E. X100). B- (Hx. \& E. X400). 

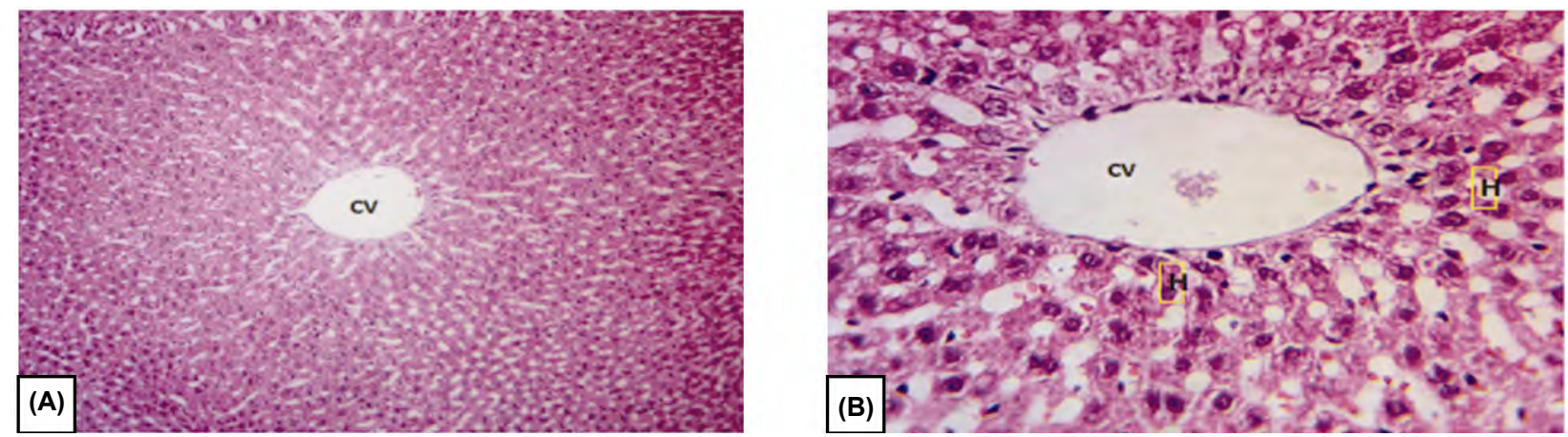

Fig. (7): (A,B): Micrograph of a rat liver (group IV), showing normal cords of hepatocytes radiating from slightly dilated central vein (CV). Some hepatocytes show vacuolated cytoplasm (H). A- (Hx. \& E. X100). B- (Hx. \& E. X400).

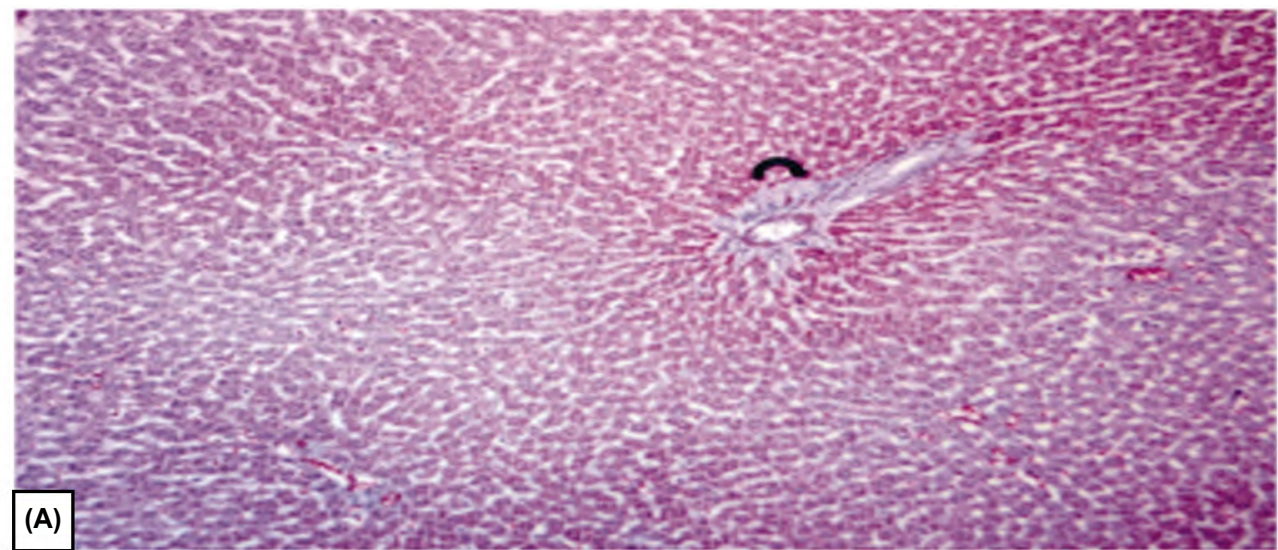

Fig. (8): (A, B, C): Micrograph of rat livers of: A- The control group, showing thin layer of collagen fibers (curved arrow) around the periportalarea. B, C- Group II, showing increased deposition of collagen fibers (red arrows) in and around the portal area. Notice: Dilated portal vein (PV) with expended portal area (black arrows). (Masson's Trichrome $\mathrm{X} 100)$.
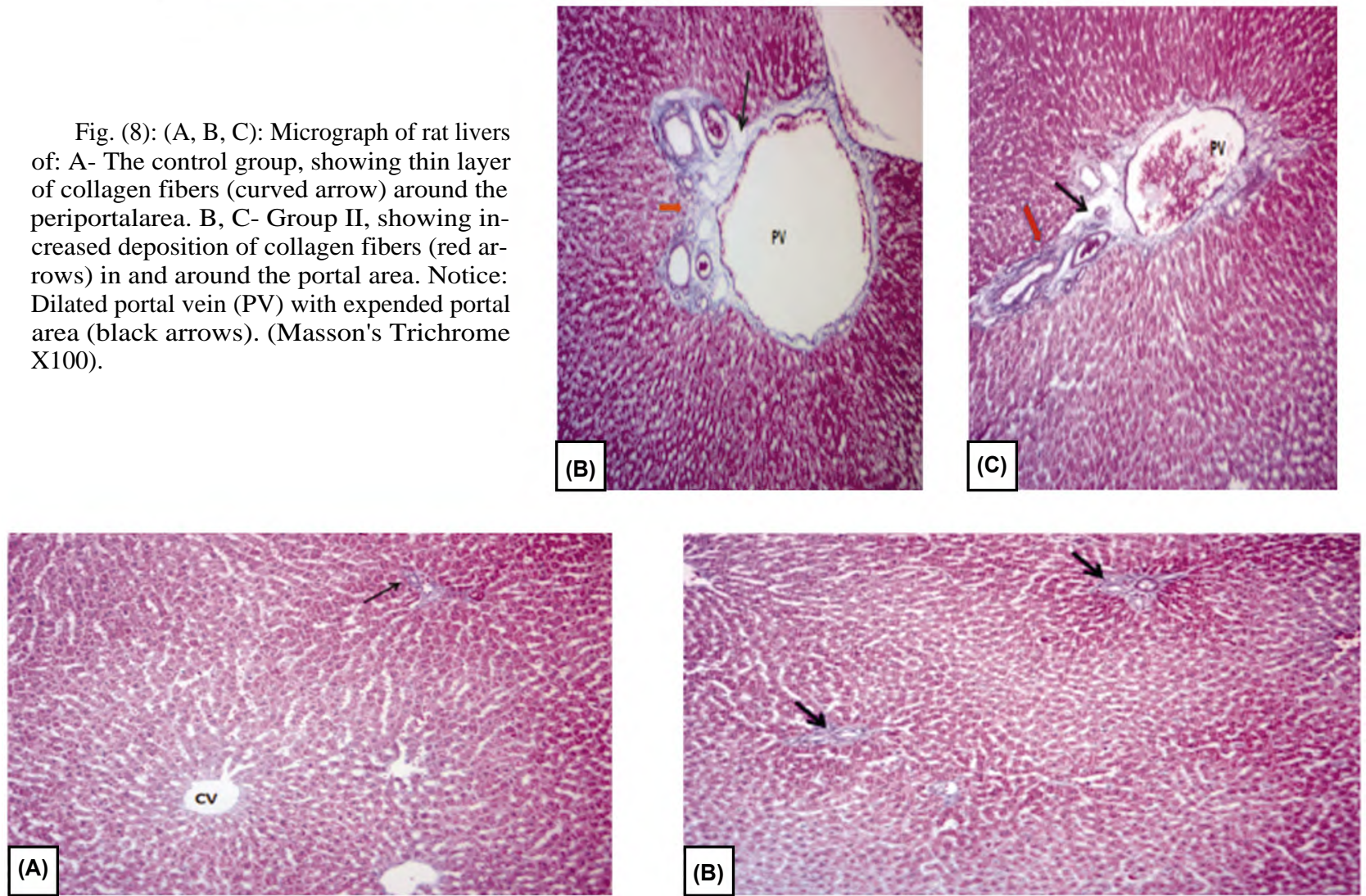

Fig. (9): (A,B): Micrograph of rat livers of: A- Group III, showing little amount of collagen fibers (black arrows) around the portal area. B- Group IV, showing little amount of collagen fibers (black arrow) around the portal area. Slightly dilated central vein is seen (CV). (Masson's Trichrome X100). 
Fig. (10): (A, B, C, D): Micrograph of rat livers: A- Group I (control group), demonstrating central vein (CV) withstrong positive PAS reaction of the glycogen content in the surrounding hepatocytes. B- Group II, showing dilated, congested central vein. The surrounding hepatocytes show weak PAS reaction (red arrows). C- Group III \& D- Group IV, presenting slightly dilated central vein $(\mathrm{CV})$. Moderate positive PAS reaction in the hepatocytes is observed. (PAS X100).
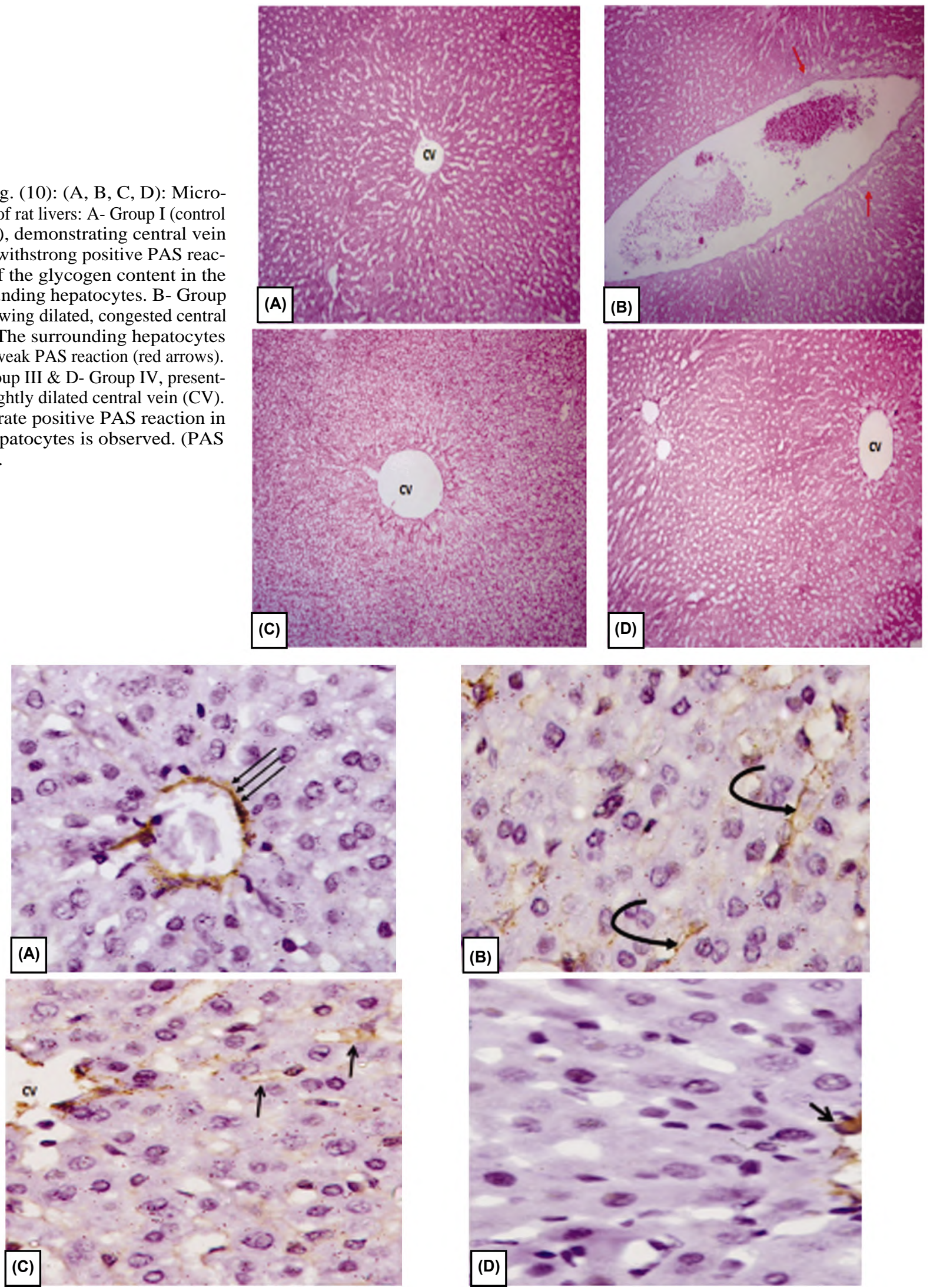

Fig. (11): (A, B, C, D): Micrograph of rat livers: A- Group I (control group), showing positive a-SMA in the wall of the central vein (black arrows). B- Group II, demonstrating positive a-SMA reaction in HSCs around blood sinusoids (curved arrows). C- Group III,displaying positive a-SMA in the wall of the central vein (CV). Moderate positive reaction was observed around blood sinusoids (black arrows). D- Group IV, illustrating positive a-SMA reaction (black arrow) in the wall of the central vein. No positive reaction was seen around blood sinusoids. ( a-SMA X400). 

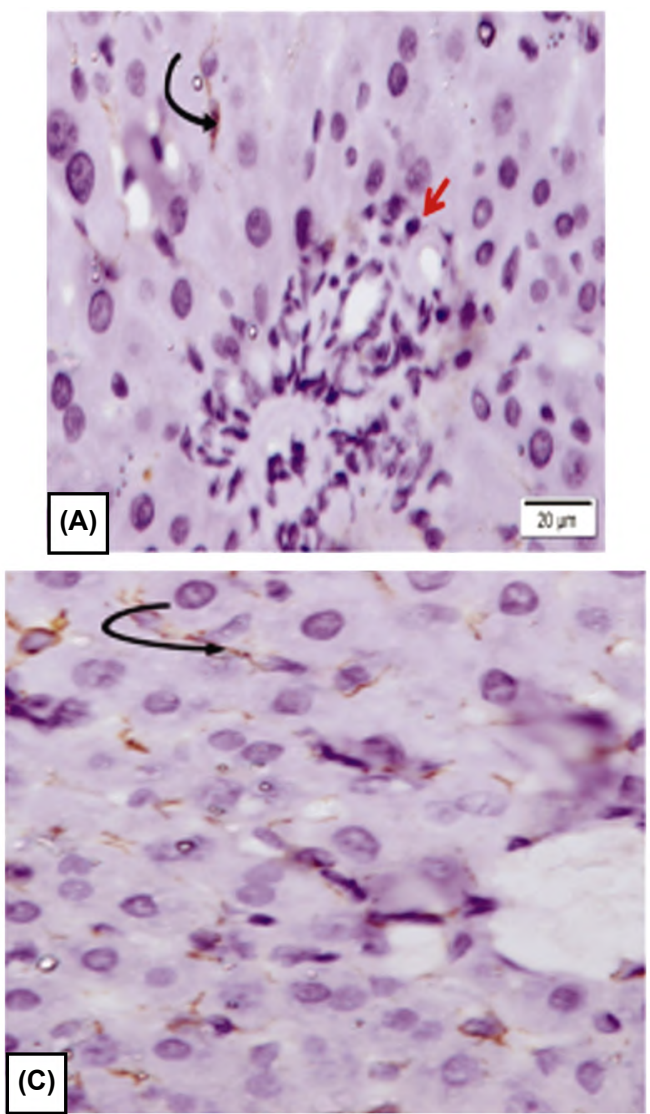
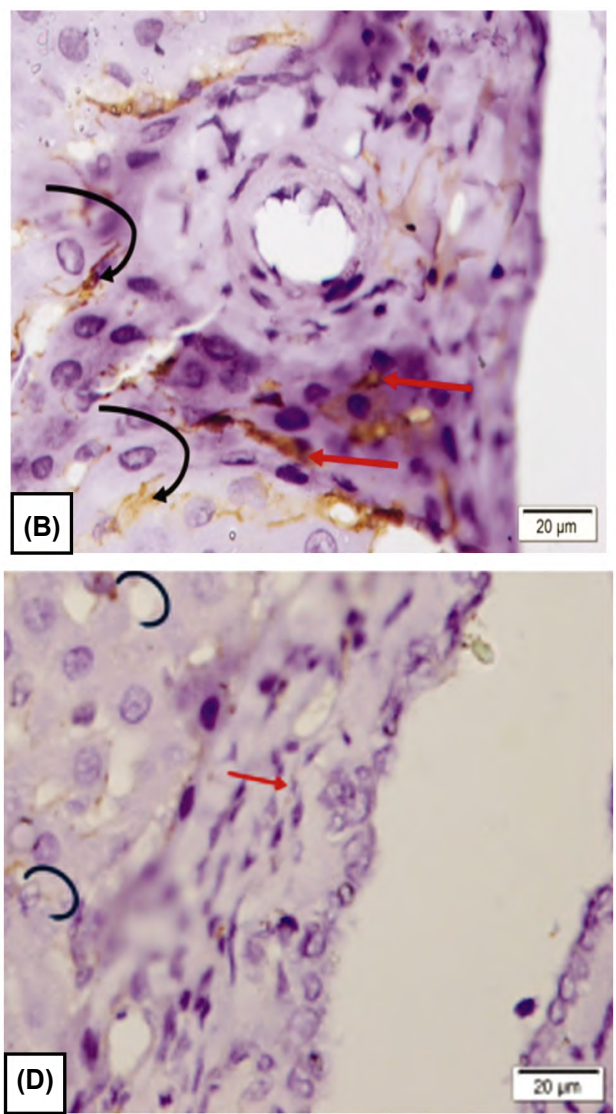

Fig. (12): (A, B, C, D): Micrograph of rat livers: A- Group I (control group), presenting GFAP positive stellate branched HSCs (curved arrows) around the blood sinusoids. No positive cells are observed at the portal area (red arrow). B- Group II, revealing GFAP positive stellate branched HSCs (curved arrows) around the blood sinusoids. Positive cells are also seen in connective tissue around the portal area (red arrows). C- Group III, exhibiting GFAP positive stellate branched HSCs (curved arrows) around the blood sinusoids. d- Group IV, exposing GFAP positive stellate branched HSCs around the blood sinusoids area (curved arrows). No positive cells are observed at the portal area (red arrow). (GFAP X400).

\section{Histomorphometric results:}

1- Collagen fibers mean area percent: Highest mean value was recorded in group II, followed by group III, then group IV, with the least mean value recorded in group I. ANOVA test revealed that the difference between groups was statistically significant $(p=0.00)$ (Table 1), Bar Chart (1).

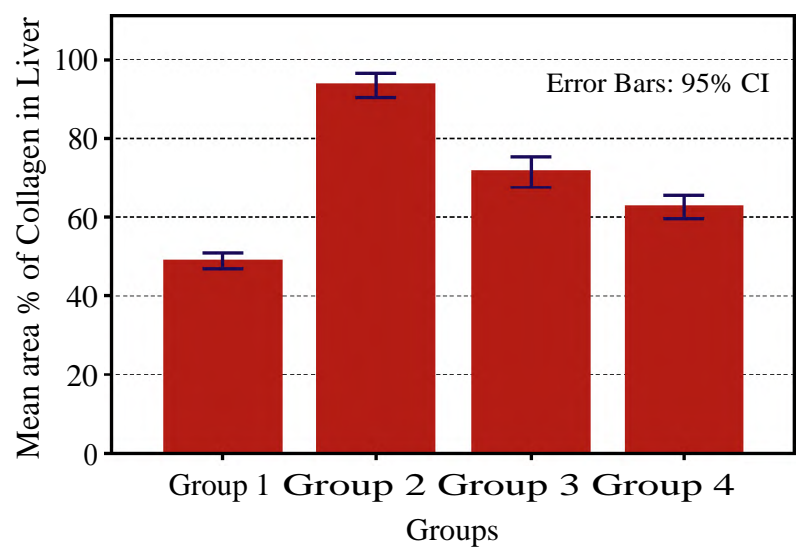

Bar Chart (1): Demonstrating mean area percent of collagen fibers in liver of different groups.
2- Glycogen optical density: The highest mean value was recorded in group I, followed by group IV, then group III, with the least mean value recorded in group II. ANOVA test revealed that the difference between groups was statistically significant $(p=0.00)$. (Table 2$)$, Bar Chart (2).

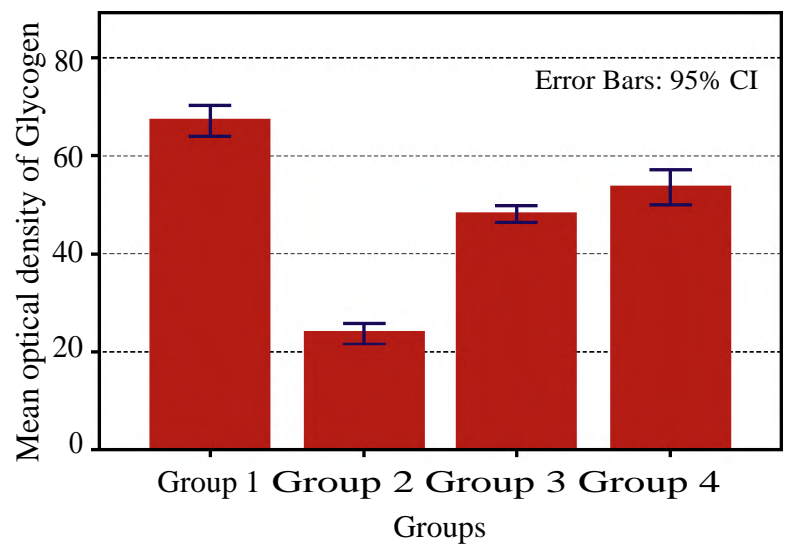

Bar Chart (2): Presenting mean glycogen optical density in liver of different groups. 
Table (1): Comparison of area percent of collagen in liver of different groups (ANOVA test).

\begin{tabular}{|c|c|c|c|c|c|c|c|c|c|}
\hline \multirow[t]{2}{*}{ Liver } & \multirow[t]{2}{*}{ Mean } & \multirow[t]{2}{*}{ Std. Dev } & \multirow[t]{2}{*}{ Std. Error } & \multicolumn{2}{|c|}{$\begin{array}{l}95 \% \text { confidence } \\
\text { interval for mean }\end{array}$} & \multirow[t]{2}{*}{ Min } & \multirow[t]{2}{*}{$\operatorname{Max}$} & \multirow[t]{2}{*}{$\mathrm{F}$} & \multirow[t]{2}{*}{$p$} \\
\hline & & & & Lower Bound & Upper Bound & & & & \\
\hline G1 & $48.78 d$ & 1.89 & .77 & 46.80 & 50.76 & 45.76 & 50.60 & 260.779 & $.000 *$ \\
\hline G2 & $93.37 \mathbf{a}$ & 2.81 & 1.15 & 90.42 & 96.32 & 89.42 & 95.83 & & \\
\hline G3 & $71.29 b$ & 3.62 & 1.48 & 67.49 & 75.08 & 66.63 & 75.35 & & \\
\hline G4 & $62.45 \mathrm{c}$ & 2.78 & 1.13 & 59.54 & 65.37 & 59.39 & 66.72 & & \\
\hline
\end{tabular}

Significance level $p<0.05, *$ : Significant.

Table (2): Comparison of glycogen optical density in liver of different groups (ANOVA test).

\begin{tabular}{|c|c|c|c|c|c|c|c|c|c|}
\hline \multirow{2}{*}{ Liver } & \multirow{2}{*}{\multicolumn{2}{|c|}{ Mean Std. Dev }} & \multirow{2}{*}{ Std. Error } & \multicolumn{2}{|c|}{$\begin{array}{l}95 \% \text { confidence } \\
\text { interval for mean }\end{array}$} & \multirow{2}{*}{ Min } & \multirow[t]{2}{*}{$\operatorname{Max}$} & \multirow[t]{2}{*}{$\mathrm{F}$} & \multirow{2}{*}{$p$} \\
\hline & & & & Lower Bound & Upper Bound & & & & \\
\hline G1 & $67.02 \mathbf{a}$ & 3.06 & 1.25 & 63.81 & 70.23 & 63.78 & 71.33 & 284.324 & $.000 *$ \\
\hline G2 & $23.79 d$ & 1.97 & .80 & 21.72 & 25.85 & 21.66 & 27.11 & & \\
\hline G3 & $48.16 c$ & 1.67 & .68 & 46.41 & 49.92 & 46.08 & 50.70 & & \\
\hline G4 & $53.46 \mathrm{~b}$ & 3.39 & 1.38 & 49.90 & 57.02 & 47.10 & 56.43 & & \\
\hline
\end{tabular}

Significance level $p<0.05$, *: Significant.

3- SMA mean area percent: Highest mean value was recorded in group II, followed by group III, then group IV, with the least mean value recorded in group I. ANOVA test revealed that the difference between groups was statistically significant $(p=0.00)$. (Table 3), Bar Chart (3).

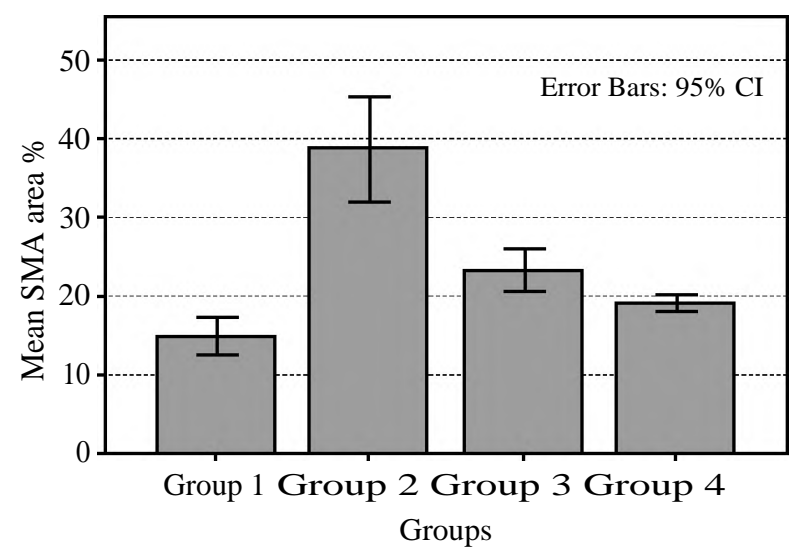

Bar Chart (3): Illustrating mean SMA area percent in liver of different groups.
4- GFAP mean area percent: The highest mean value was recorded in group II, followed by group III, then group IV, with the least mean value recorded in group I. ANOVA test revealed that the difference between groups was statistically significant $(p=0.00)$ (Table 4), Bar Chart (4).

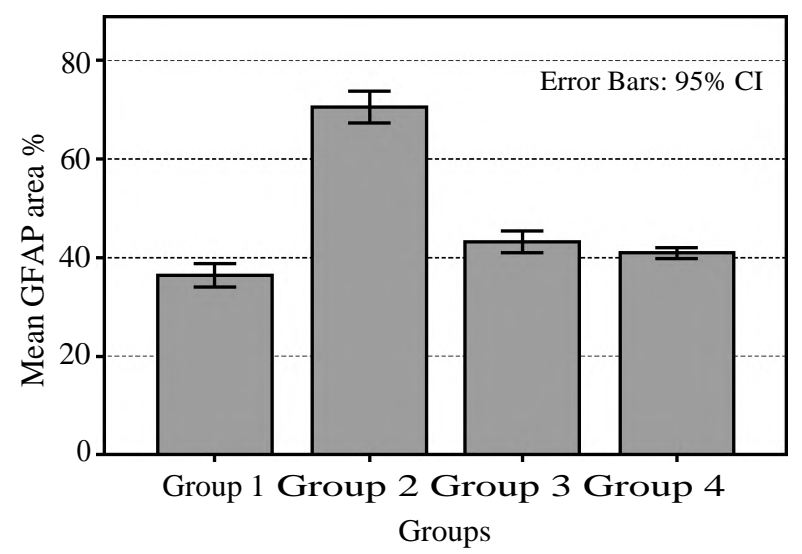

Bar Chart (4): Displaying mean GFAP area percent in liver of different groups.

Table (3): Comparison of SMA area percent in liver of different groups (ANOVA test).

\begin{tabular}{|c|c|c|c|c|c|c|c|c|c|}
\hline \multirow[t]{2}{*}{ Liver } & \multirow{2}{*}{ Mean } & \multirow{2}{*}{ Std. Dev } & \multirow{2}{*}{ Std. Error } & \multicolumn{2}{|c|}{$\begin{array}{l}95 \% \text { confidence } \\
\text { interval for mean }\end{array}$} & \multirow{2}{*}{ Min } & \multirow[t]{2}{*}{ Max } & \multirow[t]{2}{*}{$\mathrm{F}$} & \multirow{2}{*}{$p$} \\
\hline & & & & Lower Bound & Upper Bound & & & & \\
\hline G1 & $14.94 \mathrm{c}$ & 2.23 & .91 & 12.60 & 17.27 & 10.76 & 16.45 & 49.574 & $.000^{*}$ \\
\hline $\mathrm{G} 2$ & $38.73 \mathbf{a}$ & 6.31 & 2.58 & 32.10 & 45.35 & 30.31 & 46.16 & & \\
\hline G3 & $23.29 \mathrm{~b}$ & 2.54 & 1.04 & 20.62 & 25.96 & 20.54 & 26.69 & & \\
\hline G4 & $19.03 \mathbf{b}^{\prime} \mathbf{c}$ & 1.04 & $.42 \pm$ & 17.94 & 20.12 & 17.69 & 20.71 & & \\
\hline
\end{tabular}

Significance level $p<0.05, *$ : Significant. 
Table (4): Comparison of GFAP area percent in liver different groups (ANOVA test).

\begin{tabular}{|c|c|c|c|c|c|c|c|c|c|}
\hline \multirow{2}{*}{ Liver } & \multirow{2}{*}{ Mean } & \multirow{2}{*}{ Std. Dev } & \multirow{2}{*}{ Std. Error } & \multicolumn{2}{|c|}{$\begin{array}{l}95 \% \text { confidence } \\
\text { interval for mean }\end{array}$} & \multirow{2}{*}{ Min } & \multirow{2}{*}{ Max } & \multirow{2}{*}{$\mathrm{F}$} & \multirow{2}{*}{$p$} \\
\hline & & & & Lower Bound & Upper Bound & & & & \\
\hline G1 & $36.37 \mathrm{c}$ & 2.19 & .89 & 34.07 & 38.67 & 33.34 & 38.57 & 304.061 & $.000 *$ \\
\hline G2 & $70.70 \mathrm{a}$ & 2.99 & 1.22 & 67.57 & 73.84 & 66.45 & 74.35 & & \\
\hline G3 & $43.21 \mathbf{b}$ & 2.08 & .85 & 41.03 & 45.40 & 40.55 & 45.39 & & \\
\hline G4 & $40.88 \mathbf{b}$ & 1.00 & .41 & 39.82 & 41.93 & 39.59 & 42.19 & & \\
\hline
\end{tabular}

Significance level $p<0.05$, *: Significant.

\section{Discussion}

Methotrexate (MTX) was known as folic acid antagonist with anti-inflammatory, anti-proliferative and immunosuppressive activities. However, authors found that high doses of MTX caused toxicity and adverse effects on many organs as kidney, lung, central nervous system, bone marrow suppression and gastrointestinal disorders including the liver $[\mathbf{1 , 2 2 - 2 4 ]}$

The hepatotoxicity, in cases treated with MTX, was explained by its metabolism inside the liver to polyglutamated forms causing hepatotoxicity in the form of hepatitis, fatty liver, fibrosis and cirrhosis $[\mathbf{2 3 , 2 5}]$

Moreover, other studies referred hepatotoxicity to generation of Reactive Oxygen Species (ROS). The increased levels of ROS resulted in disruption of the balance between pro-oxidant and antioxidant defense system thus leading to oxidative stress and apoptosis. Oxidative stress and lipid peroxidation might be the cause of MTX-induced hepatic toxicity [26-28]. Decreased cellular levels of glutathione (GSH)-which was known to be an important antioxidant that helped in removing of free oxygen radicals and detoxification-was added to be another contributing factor [26]

In the present study, injurious effects of MTX administration were observed in the form of severe degenerative histological changes in the hepatocytes. Marked inflammatory cellular infiltration was also detected around the portal area in addition to congestion and dilatation of the portal and central veins.

The results of the present work were consistent with the studies of other authors who recorded mild fatty changes, different degrees of nuclear degeneration as apoptosis and vacuolated cytoplasm, inflammatory cellular infiltration with eosinophil in the portal area, with fibrous septa extending into the lobules [29].
The degenerative changes in the hepatocytes recorded in the present study could be explained as MTX interfered with the metabolism of folic acid through binding to the enzyme dihydrofolicreductase, thus preventing its conversion to the active form, folinic acid needed for synthesis of DNA, certain amino acids and proteins. Damage of the organelles and plasma membranes of hepatocytes led to disturbance of their function with leakage of endogenous enzymes $[6,30]$.

Inflammatory cellular infiltration was detected in the current study might be attributed to oxidative stress which stimulated the inflammatory pathway and automated cell death, apoptosis [31]. This could be explained as Cyclooxygenase- 2 enzyme (COX2) activated the conversion of arachidonic acid to prostaglandins thus promoting the inflammatory response. Caspase cascades were activated by MTX-induced oxidative stress and the accumulated pro-inflammatory cytokines. The activated caspase cascades enhanced pro-apoptotic signals and DNA fragmentation which in turn initiated programmed cell death $[32,33]$.

The present work also revealed increased amount of collagen fibers that could be explained by the direct toxic effects of MTX which induced proliferation of the hepatic fibrous connective tissue [34]

Decreased glycogen was another finding noticed after MTX injection in the current work. This might be due to defects in its synthesis as a result of degeneration of the hepatic cells accompanied by damage of mitochondria. Accordingly, reduction of mitochondrial content of the cell reduced the amount of ATP, and inhibited glycogen formation [35].

The present work showed improvement in the histological changes in groups III and IV, but the improvement was more obvious in group IV, receiving Selenium, than in group III, receiving Ursodeoxycholic Acid (UDCA). 
Ursodeoxycholic Acid (UDCA), a dihydroxy (3 $(\mathrm{x}, 70$-dihydroxy- 50 cholan-24-oic acid) bile acid, that formed $4 \%$ of total bile acid pool, was found to have beneficial effects in the treatment of liver damage induced by MTX because of its anti-oxidant effect on the hepatocytes [9].

Ursodeoxycholic acid inhibited oxidative stress induced by inflammatory cells mainly neutrophils and macrophages. These cells found to induce cellular toxicity either directly or indirectly through triggering neutrophils to secrete enzymes as elastase, and proteases and liberating oxygen radicals as MTX stimulated the movement and accumulation of white blood cells in the affected tissues thus producing more tissue damage through that way [9]

Furthermore, it was considered autoimmunity to be the cause of hepatic disorders under longterm low-dose MTX therapy. So UDCA through preventing the expression of collagen and other extracelluar matrix components, helped in treating of autoimmune liver fibrosis [13]

The anti-fibrotic activity for UDCA could be related to its ability to lower the hepatic mRNA expression of collagens [36,37]. Studies explained another mechanism for decreasing fibrosis scores in liver fibrosis by inhibiting free oxygenradicaldependent processes in the liver and by reducing the production of cytokines as tumor necrosis factor-alpha (TNFa) and tumor growth factor-beta $(\mathrm{TGFb})$. Those cytokines found to trigger apoptosis and related processes of inflammation and fibrogenesis $[\mathbf{1 1 , 1 2}]$.

Selenium (Se), a dietary antioxidant activated the cellular antioxidant thus preventing the oxidative damage [38]. Selenium prevented lipid peroxidation and improved the integrity of tissues as it enhanced Glutathione Peroxidase (GPx) activity and affecting the antioxidant/prooxidant balance of the cell $[\mathbf{3 8 , 3 9}]$. The antioxidant role of Se as a component of GPx-GSH-dependent antioxidant enzyme helped in the regeneration of liver cells through acting as a free radical scavenger and inhibited the autocatalytic process of lipid peroxidation [40].

Selenium was found to be a component of selenoproteins, so its use increased their activities, that reduced the accumulation of free radicals preventing lipid peroxidation and helped in regeneration of glutathione [41-43].

Inflammatory cellular infiltration, vacuolization and fibrosis observed in the recent study were explained by reactive oxygen species generation that interacted with biological target molecules, thus causing liver injury. Addition of that Se supplementation enhanced liver structure regeneration [18].

Studies explained the anti-inflammatory effect of $\mathrm{Se}$ as it reduced serum C-reactive protein, liver pro-inflammatory cytokines, and the expression of Nuclear Factor Kappa Beta (NF- xB) thus stopped the progression of liver injury during acute inflammatory processes [44]. It was found that deficiency in Se aggravated the cellular immune response by oxidative stress, and increased the risk of bacterial and viral infections as Se modulated the antiinflammatory and immune responses [16,45] .

\section{References}

1- WASKO M., DASGUPTA A., HUBERT H., et al.: Propensity-adjusted association of methotrexate with overall survival in rheumatoid arthritis. Arthritis Rheum., 65: 334-42, 2013

2- HAZLEWOOD G., BARNABE C., TOMLINSON G., et al.: Methotrexate monotherapy and methotrexate combination therapy with traditional and biologic disease modifying antirheumatic drugs for rheumatoid arthritis: Abridged Cochrane systematic review and network metaanalysis. B.M.J., 353: i1777, 2016.

3- SALLIOT C. and VAN DER HEIJDE D.: Risk and management of liver toxicity during methotrexate treatment in rheumatoid arthritis patients: A systematic literature research. Ann. Rheum. Dis., 68: 1100-4, 2009.

4- CHAN E. and CRONSTEIN B.: Molecular action of methotrexate in inflammatory diseases. Arthritis Res., 4: 266-73, 2002.

5- VISSER K. and HEIJDE D.: Risk and management of liver toxicity during methotrexate treatment in rheumatoid and psoriatic arthritis: A systematic review of the literature. Clin. Exp. Rheumatol., 27: 1017-25, 2009.

6- HOWARD S., McCORMICK J., PUI C., et al.: Preventing and managing toxicities of high-dose methotrexate. The oncologist, 21 (12): 1471, 2016.

7- WIDEMANN B. and ADAMSON P.: Understanding and managing methotrexate nephrotoxicity. The Oncologist, 11: 694-703, 2006.

8- RODRIGUES C., FAN G., MA X., et al.: A novel role for ursodeoxycholic acid in inhibiting apoptosis by modulating mitochondrial membrane perturbation. J. Clin. Invest., 101: 2790e9, 1998.

9- URAZ S., TAHAN V., AYGUN C., et al.: Role of ursodeoxycholic acid in prevention of methotrexate-induced liver toxicity. Digestive diseases and sciences, 53 (4): 1071-7, 2008

10- CORPECHOT C., CARRAT F., BONNAND A., et al.: The effect of ursodeoxycholic acid therapy on liver fibrosis progression in primary biliary cirrhosis. Hepatology, 32: 1196-9, 2000 
11-ZHANG L., LIANG T., TAN Y., et al.: Protective effects of ursodeoxycholic acid against immune-mediated liver fibrosis in rats. Hepato-gastroenterology, 57 (102-103): 1196-202, 2010.

12- BUKO V., LUKIVSKAYA O., ZAVODNIK L., et al.: Antioxidative effect of ursodeoxycholic acid in the liver of rats with oxidative stress caused by gamma-irradiation. Ukr. Biokhim. Zh., 74: 88-93, 2002.

13- BUKO V., KUZMITSKAYA A., NARUTA E., et al.: Ursodeoxycholic acid dose-dependently improves liver injury in rats fed a methionine and choline. Hepatol. Res., 41: 647-59, 2011

14- POPOVA N.: Perinatal selenium exposure decreases spontaneous liver tumorogenesis in CBA mice. Cancer Lett., 179: 39-42, 2002.

15- BHATTACHARJEE A., BASU A., BISWAS J., et al.: Chemoprotective and chemosensitizing properties of selenium nanoparticle (Nano-Se) during adjuvant therapy with cyclophosphamide in tumor-bearing mice. Mol. Cell Biochem., 424: 13-33, 2017.

16- ROVENSKY J., SVK K., MAT'HA V., et al.: The effects of Enterococcus faecium and selenium on methotrexate treatment in rat adjuvant-induced arthritis. Journal of Immunology Research, 11 (3-4): 267-73, 2004.

17- SCHNELL R., PARK K., DAVIES M., et al.: Protective effects of selenium on acetaminophen-induced hepatotoxicity in the rat. Toxicology and applied pharmacology, 95 (1): 1-11, 1988.

18- SAAD H., FEKI A., BOUDAWARA O., et al.: Effects of selenium on tebuconazole-induced hepatotoxicity in adult rats. Journal of Pharmacognosy and Phytochemistry, 6 (6): 105-9, 2017.

19- ELWAKEEL E. and MOHAMED Z.: The Hepatotoxic effect induced by methotrexate therapy and protective role of bone marrow-derived mesenchymal stem cells in adult male albino rats. Histological and ultrastructural study. Jounal Am. Sci., 14 (5), 2018.

20- ALHUMAIDHA K., EL-AWDAN S., EL-IRAKY W., et al.: Protective effects of ursodeoxycholic acid on ceftriaxone-induced hepatic injury in rats. Bulletin of Faculty of Pharmacy, Cairo University, 52 (1): 45-50, 2014.

21- ZHANG Q., QIAN Z., ZHOU P., et al.: Effects of oral selenium and magnesium co-supplementation on lipid metabolism, antioxidative status, histopathological lesions, and related gene expression in rats fed a high-fat diet. Lipids in health and disease, 17 (1): 165, 2018.

22- BHOJWANI D., SABIN N., PEI D., et al.: Methotrexateinduced neurotoxicity and leukoencephalopathy in childhood acute lymphoblastic leukemia. J. Clin. Oncol., 32: 949-59, 2014.

23- CONWAY R. and CAREY J.: Risk of liver disease in methotrexate treated patients. World journal of hepatology, 9 (26): 1092, 2017.

24- MAHMOUD A., GERMOUSH M., AL-ANAZI K., et al.: Commiphoramolmol protects against methotrexateinduced nephrotoxicity by up-regulating Nrf2/ARE/HO1 signaling. Biomed. Pharmacother., 106: 499-509, 2018.

25- YUCEL Y., OGUZ E., KOCARSLAN S., et al.: "The effects of lycopene on methotrexate-induced liver injury in rats," Bratislava Medical Journal, 118 (04): 212-6, 2017.
26- VARDI N., PARLAKPINAR H., CETIN A., et al.: Protective effect of beta-carotene on methotrexate-induced oxidative liver damage. Toxicol. Pathol., 38 (4): 592-7, 2010.

27- CURE E., KIRBAS A., TUMKAYA L., et al.: Protective effect of infliximab on methotrexate-induced liver injury in rats: Unexpected drug interaction. J. Cancer Res. Ther., 11 (1): 164-9, 2015.

28- MAHMOUD A., HOZAYEN W. and RAMADAN S.: Berberine ameliorates methotrexate-induced liver injury by activating Nrf2/HO-1 pathway and PPARgamma, and suppressing oxidative stress and apoptosis in rats. Biomed Pharmacother., 94: 280-91, 2017.

29- SAMDANCI E., HUZ M., OZHAN O., et al.: "Cytoprotective effects of molsidomine against methotrexate-induced hepatotoxicity: An experimental rat study," Drug Design, Development and Therapy, 13: 13-21, 2019.

30- AL-MOTABAGANI M.: Histological and histochemical studies on the effects of methotrexate on the liver of adult male albino rat. Int. J. Morphol., 24 (3): 417-22, 2006.

31- EL-SHEIKH A., MORSY M., ABDALLA A., et al.: Mechanisms of thymoquinonehepatorenal protection in methotrexate-induced toxicity in rats. Mediators Inflamm., $1-12,2015$.

32- RICCIOTTI E. and FITZGERALD G.: Prostaglandins and inflammation. Arterio-scler. Thromb. Vasc. Biol., 31 (5): 986-1000, 2011.

33- CHO H., PARK S., HEO K., et al.: Methotrexate induces apoptosis in nasal polyps via caspase cascades and both mitochondria-mediated and $\mathrm{p} 38$ mitogen-activated protein kinases/Jun N-terminal kinase pathways. Am. J. Rhinol Allergy, 27 (1): e26-e31, 2013.

34- ROS S., JUANOLA X., CONDOM E., et al.: Light and electron microscopic analysis of liver biopsy samples from rheumatoid arthritis patients receiving long-term methotrexate therapy. Scand. J. Rheumatol., 31 (6): 3306, 2002.

35- ROBBINS S. and COTRAN V.: Robbins Pathologic Basis of Disease. $7^{\text {th }}$. ed. Philadelphia. WB Saunders Company, 28, 1999.

36- TASCI I., MAS M., VURAL S., et al.: Rat liver fibrosis regresses better with pegylated interferon alpha2b and ursodeoxycholic acid treatments than spontaneous recovery. Liver Int., 26: 261-8, 2006.

37- HE H., MENNONE A., BOYER J., et al.: Combination of retinoic acid and ursodeoxycholic acid attenuates liver injury in bile duct-ligated rats and human hepatic cells. Hepatology, 53: 548-57, 2011.

38- BEN AMARA I., TROUDI A., GAROUI E., et al.: Protective effects of selenium on methimazole nephrotoxicity in adult rats and their offspring. Exp. Toxicol. Pathol., 2010.

39- KLOTZ L., KRONCKE K., BUCHCZYK D., et al.: Role of copper, zinc, selenium " and tellurium in the cellular defense against oxidative and nitrosative stress. J. Nutr., 133: 1448S-1451S, 2003.

40- SODHI S., SHARMA A., BRAR A., et al.: Effect of atocopherol and selenium on antioxidant status, lipid peroxidation and hepatopathy induced by malathion in chicks. Pest. Biochem. Physiol., 90: 82-6, 2008. 
41- GAN L., LIU Q., XU H., et al.: Effects of selenium overexposure on glutathione peroxidase and thioredoxinreductase gene expressions and activities. Biological. Trace Element. Research, 89: 165-75, 2002.

42- KLEIN E.: Selenium: Epidemiology and basic science. Journal of Urology, 171: S50-S53, 2004.

43- SEFI M., AMARA I., TROUDI A., et al.: Effect of selenium on methimazole-induced liver damage and oxidative stress in adult rats and their offspring. Toxicology and industrial health, 30 (7): 653-69, 2014.

44- AL-DOSSARI M., FADDA L., ATTIA H., et al.: Curcumin and selenium prevent lipopolysaccharide/diclofenacinduced liver injury by suppressing inflammation and oxidative stress. Biological trace element research, 1-11, 2019.

45- RAYMAN M.: "The importance of selenium to human health", Lancet, 356: 233-41, 2000.

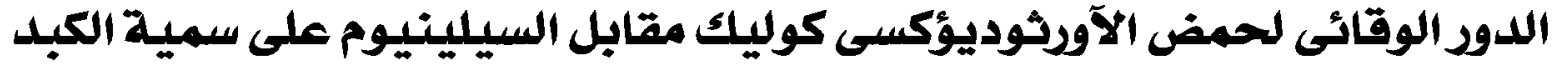

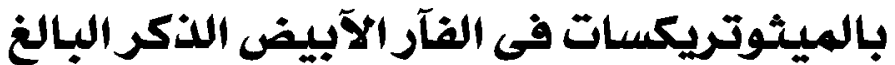

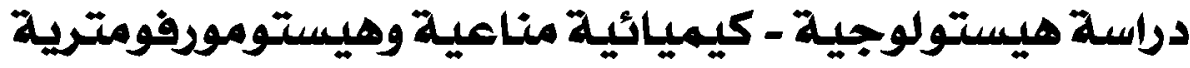

خلفية البحث: الميثوتريكسات (مضاد حمض الفوليك) هو مضاد للإلتهابات والآنشطة المضادة للتكاثر والمناعة. الميثوتريكسات وُجد آنه

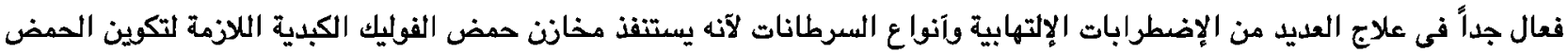

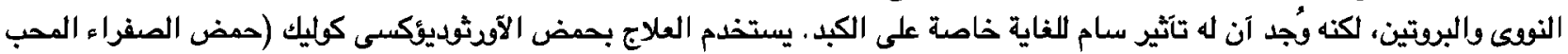

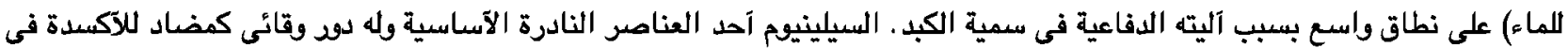
الجسم.

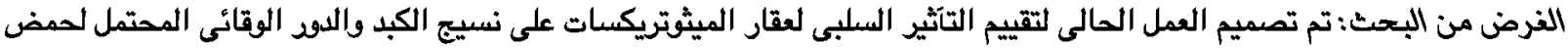

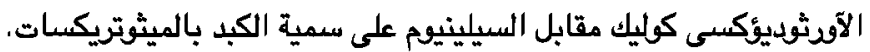

مواد البحث والطرق المستخدمة: آجريت هذه الدراسة على آربع وعشرون من الفئران البيضاء الذكور البالفة، ستة فتران لكل مجموعة:

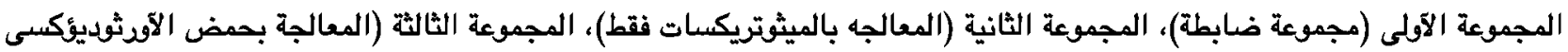

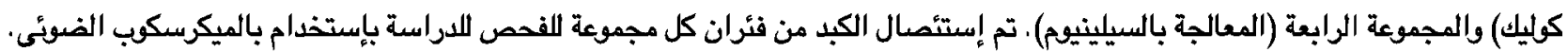

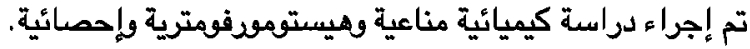

النتائج والخلاصة: آظهرت الفئران المتلقية الميثوتريكسات تغيرات تنكسية هائلة وفقدان حدود الخلايا الكبدية. تم إستعادة هذه التغييرات

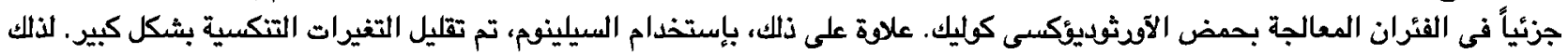

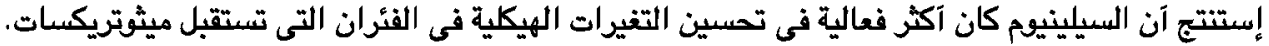

